\title{
О.Г. Шишков
}

Академия медиаиндустрии, ГБУ «Мосстройинформ»

Д.А. Антипин

Комплекс градостроительной политики и строительства Москвы

Я.А. Пархоменко

Академия медиаиндустрии

\section{ГРАДОСТРОИТЕЛЬНАЯ ПОЛИТИКА: \\ СПЕЦИФИКА РАБОТЫ С ВИЗУАЛЬНЫМИ ОБРАЗАМИ И ПЕРЕХОД ОТ КЛАССИЧЕСКИХ МЕДИА В ПРОСТРАНСТВО НОВЫХ МЕДИА}

\begin{abstract}
Анализируются базовые принципы производства контента для освещения вопросов градостроительной политики. Контент разделяется на два типа, и вводится определение для них. Рассматриваются особенности производства, и ставится вопрос об изменении базовых принципов производства контента при переходе в пространство Новых медиа.
\end{abstract}

Ключевые слова: контент, градостроение, архитектура, медиа, визуальный, образ, дополненная реальность

Тема градостроения занимает треть от всей информационной повестки городских властей Москвы в медиа (по данным Медиалогии на 20.12.2019), при том что как минимум 20\% городских медиа пользуются вниманием граждан (при среднем показателе более 400 тыс. уникальных посетителей в месяц городских медиа, по данным Similarweb) [1, с. 22]. Вопросы градостроительной политики относительно легко освещать вербально, в связи с тем, что в основе большинства информационных сообщений лежат лаконичные данные, содержащие в себе фактические сведения, цифры и другие чётко измеряемые величины. Однако современные информационные сообщения существуют в мультимедиа пространстве и состоят из двух компонент: вербальной и визуальной, которые, безусловно, находятся в постоянном взаимо- 
действии, обогащают и дополняют друг друга. Кроме того, технологии сделали доступным для обычного пользователя и виртуальное трёхмерное пространство в формате дополненной реальности (AR) $[2$, с. 2]. На фасадах зданий стали появляться QR- коды, за которыми могут скрываться модели дополненной реальности. Многие муниципалитеты стали размещать таблички с такими кодами, ведущими на информационные ресурсы.

Рассмотрим специфику построения визуальной компоненты информационного сообщения в контексте освещения градостроительных вопросов. «Архитектурное сооружение - всегда образ, т. е. способ и форма освоения действительности в искусстве» [3, с. 33]. Любое визуальное сообщение базируется на принципе формирования визуальных образов. Вообще визуальные образы достаточно информационно ёмкие и могут существовать без вербального подкрепления. Если составляющей визуального образа является человек, то в большинстве случаев, в методологическом плане, данный процесс формирования визуального образа не вызывает особых трудностей. Однако если мы формируем повествование на основе визуальных образов, где человек отсутствует или не является сюжетно значимой частью, то начинают проявляться разбираемые нами в рамках статьи особенности. Как упоминалось ранее, информационное сообщение состоит из двух компонент: вербальной и визуальной. Будем считать, что визуальная компонента, в свою очередь, в мультимедиа пространстве современного цифрового мира бывает двух видов: статического и динамического. Для более точного понимания введем определения: статическим изображением мы будем называть изображение, которое остается неизменным во времени само по себе, любые изменения происходят только посредством воздействия наблюдателя (приближение-отдаление, повороты, изменение ракурса), без изменения целостности визуального пространства самого изображения, драматургия и художественная значимость определяются целостностью и законченностью изображения самого по себе; динамическим изображением будем называть изображение, в котором визуальное пространство претерпевает изменения с течением вре350 
мени само по себе и наблюдатель может влиять только на скорость воспроизведения, драматургия и художественная значимость раскрываются во времени, где законченность и целостность также могут быть динамичными. Данные определения применимы в контексте этой статьи и требуют уточнения в случае развития технологий. Таким образом, если рассматривать вопрос с позиции траектории эволюции информационного сообщения, то видим, что в классических медиа в дотелевизионную эпоху были только статические визуальные образы (газеты и журналы, без учёта киножурналов), с приходом телевидения присутствуют динамические визуальные образы. Таким образом, в классических медиа визуальные образы - статические в печатных, динамические на телевидении. Если статические вставки и были на телевидении, то они играли роль спецэффекта и несли эмоциональную нагрузку (эффект двойного подкрепления). В эру интернета и мультимедиаресурсов генерации WEB 2.0 и 3.0 - на равных правах присутствуют как статические визуальные образы, так и динамические.

Статические образы в пространстве мультимедиа претерпели эволюционное развитие: от фотографий, «вшитых» в текст web-страницы, до масштабируемых картинок и объёмных изображений. Вся художественная палитра статичных визуальных образов очень хорошо «играет» на формировании информационного сообщения в тематике архитектуры и градостроения. Статичное изображение является наиболее эмоционально насыщенным и информативно ёмким при художественном формировании визуального образа статичного объекта, каковыми являются архитектура и строительные объёмы. И современные инновации, такие как сшивание изображений в объёмные картинки с возможностью изменения ракурса обзора, в градостроительной и архитектурной тематике наиболее востребованы и выразительны - как в прикладном значении, так и эстетическом. «Архитектура часто представлена в фотографии. Снимки получаются очень интересными, так как при сооружении зданий авторы стараются во внешний вид вложить максимум своего мастерства и художественного вкуса. Кроме того, архитекторы стремятся 
разместить сооружение таким образом, чтобы оно гармонировало с пейзажем. Поэтому архитектура занимает особое место в жанре фотографии» [4, с. 39]. Кроме того, следует отметить, что по многим темам информационных сообщений стилистически затруднительно увязывать фотографию и графику, цветную фотографию и черно-белую, растровую графику и векторную. Однако градостроительная тематика с легкостью увязывает в одном информационном сообщении фотографию и графику, а также комбинации их различных жанров. Возьмём на себя смелость заявить, что это связано с тем, что если сюжетно значимой частью визуальных образов градостроительной тематики являются статичные объекты, а именно архитектурные сооружения или строительные объёмы, то общее восприятие этого информационного сообщения не страдает из-за жанрового совмещения различных типов: цветной фотографии, черно-белой, растровой графики и векторной графики. И как раз этот фактор создает сложности при вписывании в статичное изображение, где сюжетно значимая часть сформирована вокруг архитектурного объекта, — человека как динамического объекта самого по себе. В традиции формирования композиции изображения (кадра) человек является точкой отсчёта, габариты человека позволяют зрителю оценивать размеры и пропорции архитектурного сооружения или строительного объёма. [5, с. 84]. Статичное изображение практически нивелирует данный фактор и, таким образом, он возникает только в момент создания изображения, т. е. эта сложность возникает только у фотографа. «Когда человек проецируется крупным планом на фоне какого-либо сооружения, а оно, будучи дальним планом, дано мелко, складывается превратное представление о подлинных размерах здания ... В горизонтально построенных кадрах фигура человека должна занимать примерно половину кадра по высоте, а в вертикальных - одну треть» [6, с. 93]. В свою очередь редактор стилистически легко верстает статичные изображения, где сюжетно значимую часть композиции кадра занимает архитектурное сооружение, в печатную или web-страницу. 
Методология работы с динамичными изображениями претерпела два этапа своего эволюционного развития. Рубежом является возникновение WEB 3.0 - переход от формата взаимодействия с контентом «либо чтение, либо запись» в формат интерактивного взаимодействия «чтение-запись». «Если платформа Web 2.0 выступала в качестве своеобразного коллективного разума, где каждый мог формировать и обновлять информацию в форматах Новых медиа (LiveJournal, YouTube, Wikipedia и т.п.), то наступление Web 3.0 - это не только появление модерированного экспертным сообществом информационного наполнения, но и создание семантической паутины в рамках всего цифрового контента» [7, с. 115]. На первом этапе динамичное изображение создавалось по большей части для телевидения, где соотношение сторон 3:4, что, в свою очередь, удобно для построения композиции кадpa, где сюжетно значимой частью является человек, и не удобно для выстраивания композиции вокруг архитектурных сооружений и строительных объёмов. Дело в том, что человек имеет вертикальную пропорцию, а большинство архитектурных сооружений и строительных объёмов - горизонтальную: «пропорции кадра и взаимоотношение объектов с границами изображения оказывают существенное влияние на композицию кадра. В искусстве фотографии исторически сложилось два базовых формата изображения: горизонтальная фотография для съёмки пейзажей и вертикальная - для портретной» [5, с. 54]. Здесь следует сделать отступление для прояснения нескольких нюансов - большая часть телевизионного контента относится к жанру репортажа, где человека снимают крупным и средним планом, а изображение архитектуры в большинстве случаев относят к так называемым адресным планам, которые, в свою очередь, снимают общими и сверхобщими, где человек не бывает сюжетно значимой частью композиции. «В фильмах и передачах нам, как правило, необходимо создать ОБРАЗ города, улицы, здания, соответствующий общей драматургической задаче всего экранного произведения» [3, с. 33]. В данном контексте существовал консенсус до тех пор, пока телевидение не перешло на формат $\mathrm{HD}$, где соотношение сторон стало кине- 
матографическим 16:9. Что в свою очередь создало проблему для формирования композиции кадра вокруг фигуры человека как сюжетно значимой части изображения (человек - «вертикальный», строения - «горизонтальные»), но упростило формирование уравновешенного кадра, где сюжетно значимой частью являются архитектура и строительные объемы. При работе в пространстве тем, посвященных архитектурной и строительной тематике, в основном ставится задача построения визуального образа с доминированием архитектуры и строительных объёмов, даже если присутствует в кадре человек, то он выполняет задачу вербального подкрепления визуального образа. Таким образом, мы опять соприкасаемся с обозначенной ранее проблемой статичного и динамичного - архитектурные объекты статичны по своей сути, человек динамичен. И всё это «упаковано» в динамичное изображение. Традиционным художественным приёмом в данном случае были: панорамирование и зумм (динамичное изменение крупности). В случае если драматургически необходимо присутствие рассказчика в кадре, то панорамирование или зумм сопровождаются перемещением человека внутри кадра - таким образом решается вопрос динамического изображения со статическим объектом или, иными словами, мы статичному объекту придаём динамику через художественный приём. «Иллюзию движения объектов можно получить, панорамируя по неподвижным предметам, что придаст изображению динамический момент» $[8$, с. 51]. Однако в данном случае тоже есть важный нюанс - если человек в кадре присутствует с вербальным сообщением, то художественно оправданно его снимать крупным планом или средним, однако на крупном плане пропадает композиционная значимость архитектурных объектов, а на среднем плане сложно построить равновесную композицию с человеком и архитектурным объектом. Эту проблему обходят тем, что не используют средний план, а строят композицию на общем плане с драматургическим приёмом - глубинной мизансцены, когда персонаж во время своего вербального подкрепления передвигается внутри кадра, а камера меняет крупность от общего плана к среднему (крупному) с выходом на средний 354 
план (крупный) человека. Но в таком случае пропадает драматургия мимики лица, т. к. укрупнение обычно является финалом этого плана. В таком случае используется драматургия пластики тела и жестикуляции.

Второй этап работы с динамическим изображением был обусловлен развитием технологий как производства контента, его размещение и воспроизведение. Следует заметить, что спектр художественных решений при производстве контента на градостроительную тематику ограничен в первую очередь самим предметом разработки - архитектурой. Архитектурные объекты и строительные объёмы крупные, протяженные и масштабные, когда их несколько. Появление новых технологий для производства контента расширило спектр художественных решений. Будем рассматривать только те, которые финансово и технически доступны для малого и среднего продакшена. В первую очередь, это квадрокоптеры с функцией видеозаписи. Квадрокоптеры открывают третью стихию для производителей контента - воздух. Использование летающей камеры открывает ракурсы съёмки, доступные ранее только проектировщикам и архитекторам, кроме того, появляются новые художественные решения — облёт по сложным траекториям, приближение и удаление из недоступных ранее ракурсов. Съёмка цейтрафером - когда динамика изображения создается за счет изменения окружающего пространства (движение солнца, изменения на небе, движение людей и автомобилей).

Однако дальнейшее развитие технологий подводит нас к следующему этапу в производстве динамического контента. Сейчас основной трафик производства и потребления контента уходит на мобильные платформы в пространство Новых медиа. Но у мобильных платформ есть особенность производства контента - он имеет портретную ориентацию (вертикальную), а не альбомную (горизонтальную), как у классических медиа. Сейчас контент производится как вертикальный, так и горизонтальный, квадратный — в Instagram. Но основным концептом Новых медиа является то, что потребитель контента сам же его и производит. А эргономически мобильное устройство удобнее держать вертикально. В связи с этим современные приложения для 
мобильных устройств производятся с вертикально ориентированным интерфейсом без возможности адаптации под горизонтальную ориентацию (TikTok) [9], что подталкивает пользователя производить контент с портретной ориентацией (вертикальной). А это, как разобрали ранее, абсолютно не подходит, в рамках традиционных художественных решений и творческих ходов, для формирования визуальных образов архитектуры и строительных объёмов. Сейчас мы находимся в фазе перехода от уже классических художественных решений и творческих ходов, когда они просто встраиваются в Новые медиа без адаптации, но уже начинают формироваться новые драматургические и художественные решения для формата Новых медиа, которые, может быть, и будут иметь некоторые родовые признаки и преемственность прежних, но, скорее всего, будут по своей сути абсолютно новыми и оригинальными. Кроме того, в поведенческую модель уже встроился паттерн использования QR-кодов, ведущих на различные ресурсы, а продакшн-студии перешли от экспериментов с дополненной реальностью, к коммерческому производству контента [2, с. 3]. AR - сшивает контент, существующий гдето на устройстве с пространством нашего существования. Если до этого момента пользователь был в «состоянии классической физики» - либо занят контентом, либо реальной жизнью,- то появление дополненной реальности в коммерческой эксплуатации переводит пользователя в «квантовомеханическое состояние» - одновременное потребление контента и жизнь в реальном мире. Это существенно расширяет спектр художественных решений и многообразие творческих ходов для производителя контента, что приведёт к кратному увеличению объёмов производимого продукта.

\section{Список литературы}

1. Город и медиа: материалы Международной научнопрактической конференции «Новые городские медиа в медиаландшафте России» / Перм. гос. нац. исслед. ун-т. - Пермь, 2018. - 236 с. 
2. Малыгина Л.Е. Дополненная реальность в ТВ-промодискурсе // Учёные записки Новгородского государственного университета имени Ярослава Мудрого. - 2019. - №1 (19) [Электронный ресурс]. - URL: https://doi.org/10.34680/dsj9-fh77 (дата обращения: 30.09.2020).

3. Волынец М.М. Принципы работы оператора при съёмке архитектурных сооружений. - М.: Институт повышения квалификации работников телевидения и радиовещания, 2009. - 46 с.

4. Дегтярев А.Р. Фотокомпозиция: Средства. Формы. Приёмы. М.: Издательство ФАИР,2009. - 272 с.

5. Уорд П. Композиция кадра в кино и на телевидении. - М.: Издательство ГИТР,2005. - 196 с.

6. Курский Л.Д. Фельдман Я.Д. Иллюстрированное пособие по обучению фотосъёмке. - М.: Высшая школа, 1991. - 160 с.

7. Лисенкова А.А. Новые медиа: от WEB 1.0 к семантической паутине WEB 4.0 // Вестник МГУКИ. - 2018. - №1 (81) [Электронный pecypc]. - URL: https://cyberleninka.ru/article/n/novye-media-ot-web-1-0-ksemanticheskoy-pautine-web-4-0 (дата обращения: 30.09.2020).

8. Медынский С.Е. Панорамирование как творческий приём оператора-документалиста // Институт повышения квалификации работников телевидения и радиовещания. - М., -2003.- 67 с.

9. Вертикальные видео зло? Видеосьемка [Электронный ресурс]. - URL: https://www.youtube.com/watch?v=DiNgT2gJd24\&t=365s _дата обращения: 30.09.2020).

\author{
O. G. Shishkov \\ Academyofmediaindustry, Mosstroiinform
}

D.A. Antipin

Complexofurbanplanningpolicyand construction of Moscow

Ya. A. Parkhomenko

Academy of media industry 


\section{URBAN PLANNING POLICY: THE SPECIFICS OF WORKING WITH VISUAL IMAGES AND THE TRANSITION FROM CLAS- SICAL MEDIA TO THE SPACE OF NEW MEDIA}

The basic principles of content production for coverage of urban policy issues are analyzed. Content is divided into two types, and a definition is entered for them. The article considers the features of production, and raises the question of changing the basic principles of content production during the transition to the New media space.

Keywords: content, urban planning, architecture, media, visual, image, augmented reality. 